\title{
Calcitonin gene-related peptide protects type II alveolar epithelial cells from hyperoxia-induced DNA damage and cell death
}

\author{
HONGMIN FU ${ }^{1}$, TIESONG ZHANG ${ }^{1}$, RONGWEI HUANG ${ }^{1}$, ZHEN YANG $^{1}$, \\ CHUNMING LIU ${ }^{1}$, MING LI ${ }^{1}$, FANG FANG ${ }^{2}$ and FENG XU ${ }^{2}$ \\ ${ }^{1}$ Department of Pediatric Internal Medicine, Children's Hospital, Kunming Medical University, Kunming, Yunnan 650032; \\ ${ }^{2}$ Pediatric Intensive Care Unit, Children's Hospital, Chongqing Medical University, Chongqing 400014, P.R. China
}

Received November 27, 2015; Accepted November 25, 2016

DOI: $10.3892 /$ etm.2017.4132

\begin{abstract}
Hyperoxia therapy for acute lung injury (ALI) may unexpectedly lead to reactive oxygen species (ROS) production and cause additional ALI. Calcitonin gene-related peptide (CGRP) is a 37 amino acid neuropeptide that regulates inflammasome activation. However, the role of CGRP in DNA damage during hyperoxia is unclear. Therefore, the aim of the present study was to investigate the effects of CGRP on DNA damage and the cell death of alveolar epithelial type II cells (AEC II) exposed to $60 \%$ oxygen. AEC II were isolated from 19-20 gestational day fetal rat lungs and were exposed to air or to $60 \%$ oxygen during treatment with CGRP or the specific CGRP receptor antagonist $\mathrm{CGRP}_{8-37}$. The cells were evaluated using immunofluorescence to examine surfactant protein-C and ROS levels were measured by probing with $2^{\prime}, 7^{\prime}$-dichlorofluorescin diacetate. The apoptosis rate and cell cycle of AEC II were analyzed by flow cytometry, and apoptosis was determined by western blotting analysis of activated caspase 3 . The DNA damage was confirmed with immunofluorescence of H2AX via high-content analysis. The ROS levels, apoptotic cell number and the expression of $\gamma \mathrm{H} 2 \mathrm{AX}$ were markedly increased in the hyperoxia group compared with those in the air group. Concordantly, ROS levels, apoptotic cell number and the expression of $\gamma \mathrm{H} 2 \mathrm{AX}$ were significantly lower with a significant arrest of $\mathrm{S}$ and $\mathrm{G} 2 / \mathrm{M}$ phases in the $\mathrm{CGRP} / \mathrm{O}_{2}$ group than in the hyperoxia or $\mathrm{CGRP}_{8-37} / \mathrm{O}_{2}$ groups. CGRP was concluded to protect lung epithelium cells against hyperoxic insult, and upregulation of CGRP may be a possible novel therapeutic target to treat hyperoxic lung injury.
\end{abstract}

Correspondence to: Dr Feng Xu, Pediatric Intensive Care Unit, Children's Hospital, Chongqing Medical University, 136 Zhongshan 2nd Road, Chongqing 400014, P.R. China

E-mail: xufeng67@yeah.net

Key words: hyperoxia, alveolar epithelial type II cell, calcitonin gene-related peptide, acute lung injury, DNA damage

\section{Introduction}

Acute lung injury (ALI), characterized by severe alveolar damage, results from an acute inflammatory response that leads to edema, neutrophil and macrophage infiltration (1). Development of ALI is a common cause for admission to critical care units, with incidence in intensive care units recently reported to be $10.4 \%$ (2). Severe sepsis is the most common risk factor for the development of ALI $(2,3)$. Hyperoxia therapy is a useful part of treatment for patients with acute and chronic cardiovascular and pulmonary diseases (4). However, prolonged exposure to hyperoxia may cause additional deterioration in cases of ALI (5). Acute exposure to hyperoxia induces lung inflammation and injury, leading to impairment in respiratory function (6). Prolonged exposure to high concentrations of oxygen $(>50 \%)$ may lead to acute or chronic lung damage, which is characterized by dysfunction of alveolar epithelial cells (AEC), repressed proliferation and increased apoptosis and cell death $(7,8)$. Hyperoxic injury is mediated by accumulation of inflammatory factors and direct insult resulting from reactive oxygen species (ROS) (9).

Calcitonin gene-related peptide (CGRP) is a 37 amino acid neuropeptide that is mainly synthesized and distributed in the $\mathrm{C}$ fibers of sensory nerves in humans and mammals. It is also the predominant neuromediator to induce vasodilation and neurogenic inflammation (10). However, a previous study indicated that CGRP also serves a role in anti-inflammatory actions and tissue repair, as it decreases interleukin (IL)-8 secretion, suppresses the formation of ROS and induces proliferation in the epithelium (11). ROS are often associated with DNA damage and repair in acute lung injury $(12,13)$. Previous studies reported that a number of drugs reduce the death of lung epithelial cells by blocking DNA damage (14-17). Whether CGRP has the same effects on hyperoxia-injured AEC II is unknown. The present study was designed to evaluate the role of CGRP in a hyperoxic cell model (60\% oxygen for $24 \mathrm{~h}$ ) in AEC II isolated from fetal rats at 19-20 days old, and to investigate whether the mechanism involved DNA damage repair.

\section{Materials and methods}

Suppliers of reagents. Reagents were obtained as follows: Trypsin, DNase I, Dulbecco's minimal essential medium/F12 
(DMEM/F12) and fetal calf serum (FCS) were obtained from Gibco (Thermo Fisher Scientific, Inc., Waltham, MA, USA); bovine serum albumin (BSA), propidium iodide and collagenase I was purchased from Sigma-Aldrich (Merck Millipore, Darmstadt, Germany); CGRP and CGRP ${ }_{8-37}$ were sourced from Anaspec Inc. (Freemont, CA, USA); methylenedioxyamphetamine (MDA) and lactate dehydrogenase (LDH) kits were obtained from Jiancheng Biological Engineering Research Institute (Nanjing, China); Annexin V-fluorescein isothiocyanate (FITC) kits were from Jingmei Biotech Co. Ltd. (Shenzhen, China); TRlzol was from Tiangen Biotech Co., Ltd. (Beijing, China); goat anti-rabbit immunoglobulin (Ig) G/FITC (cat. no. sc-2012) and rabbit anti-surfactant protein (SP)-C polyclonal antibody (cat. no. sc-13979) were from Santa Cruz Biotechnology, Inc. (Dallas, TX, USA); Alexa Fluor 488-conjugated anti-rabbit IgG antibody (cat. no. A-11008) and Hoechst 33342 were obtained from Molecular Probes (Thermo Fisher Scientific, Inc.); and rabbit polyclonal $\gamma \mathrm{H} 2 \mathrm{AX}$ (phospho S139) antibody (cat. no. ab2893) was from Abcam (Cambridge, UK).

Isolation and culture of fetal rat AEC II. Fetal rat AEC II at the canalicular stage (at 19-20 days of gestation), were isolated using a previously described method (17). All experiments were approved by the Animal Care Committee of Kunming Medical University. Briefly, 30 pregnant Sprague-Dawley rats (Vital River Laboratories Co.,Ltd., Beijing, China), with a mean weight of $264 \mathrm{~g}$ (range, 214-307 g) at 19-20 days of gestational were anesthetized by intraperitoneal injection of pentobarbital $(200 \mathrm{mg} / \mathrm{kg}$ ), and fetal rats were extracted following onset of adequate anesthesia. Fetal lungs were lysed and digested with $0.125 \%$ trypsin and $10 \mathrm{mg} / \mathrm{ml} \mathrm{DNase}$ for $25 \mathrm{~min}$ at $37^{\circ} \mathrm{C}$. Trypsinization was stopped with DMEM/F12 with $10 \%$ FCS and cells were centrifuged at $800 \times \mathrm{g}$ for $5 \mathrm{~min}$. Supernatants were removed and cell pellets were resuspended and incubated in collagenase for $15 \mathrm{~min}$ at $37^{\circ} \mathrm{C}$. The collagenase reaction was stopped by adding serum, followed by centrifugation, as above. Cell pellets were resuspended and plated into 6-well plates, which were incubated for $1 \mathrm{~h}$ at $37^{\circ} \mathrm{C}$, for differential adherence to remove fibroblasts, as non-adherent cells were gently panned and recovered. Purified cells were plated in 6-well plates at a seeding density of $1 \times 10^{6}$ and grown to $70-80 \%$ confluence over $15-18 \mathrm{~h}$ in DMEM/F12 supplemented with $10 \% \mathrm{FBS}$. Cultures were maintained at $37^{\circ} \mathrm{C}$ in a humidified atmosphere supplemented with $5 \% \mathrm{CO}_{2}$ for $24 \mathrm{~h}$, prior to analysis. The purity of AEC II cells was demonstrated to be $>90 \%$ by immunostaining for SP-C (18).

Exposure to air or hyperoxia. AEC II cells were inoculated on cover slides in a 6-well plate and grown to $70-80 \%$ confluence. Following this, $10 \mu \mathrm{M}$ CGRP or both CGRP and $100 \mu \mathrm{M}$ $\mathrm{CGRP}_{8-37}$ (a specific CGRP receptor antagonist), in accordance with pre-test results by sequential titration, were added into medium prior to exposure to hyperoxia or air. Hyperoxia was achieved by placing plates in a modular chamber and filling the chamber with a gas mixture of $60 \%$ oxygen and $5 \% \mathrm{CO}_{2}$ until this condition was stable with the chamber. The 'air' condition was accomplished by filling the chamber with air containing $5 \% \mathrm{CO}_{2}$. Following this, the hyperoxia and air chambers were sealed and put into a $37^{\circ} \mathrm{C}$ incubator for $24 \mathrm{~h}$, with continuous monitoring on oxygen fraction of air using a Pigeon I oxygen measuring meter (Pigeon Medical Apparatus Co., Ltd., Guangzhou, China).

The experiments were performed in six groups as follows: i) Air group, cells were cultured in the 'air' conditions (as above); ii) CGRP/air group, cell medium had $10 \mu \mathrm{M}$ CGRP added 30 min before culturing in air (as above); iii) $\mathrm{CGRP}_{8-37} /$ air group, CGRP and $100 \mu \mathrm{M} \mathrm{CGRP}_{8-37}$ were added before culturing in air (as above); iv) hyperoxia group, cells were cultured in the 'hyperoxia' conditions (as above); v) $\mathrm{CGRP} / \mathrm{O}_{2}$ group, $10 \mu \mathrm{M}$ CGRP was added into the medium $30 \mathrm{~min}$ before hyperoxia exposure; and vi) $\mathrm{CGRP}_{8-37} / \mathrm{O}_{2}$ group, CGRP and CGRP $_{8-37}$ were added into the culture medium $30 \mathrm{~min}$ before hyperoxia treatment.

Immunofluorescence assay for SP-C.AEC II cells were cultured for $15-18 \mathrm{~h}$ and treated with $\mathrm{CGRP}$ and $\mathrm{CGRP}_{8-37}$ before exposure to air or $60 \%$ oxygen, as described above. After $24 \mathrm{~h}$, the slides were removed and rinsed three times with ice-cold PBS. Cells were then fixed with methanol for $15 \mathrm{~min}$ at $-20^{\circ} \mathrm{C}$, rehydrated twice with PBS, then blocked with $1 \% \mathrm{BSA}$ for $10 \mathrm{~min}$ at room temperature. After incubation overnight at $4^{\circ} \mathrm{C}$ with specific SP-C (1:500) and $\gamma \mathrm{H} 2 \mathrm{AX}$ (phospho S139; 1:200) antibodies, the slides were rinsed extensively with PBS, and incubated with a FITC-conjugated secondary antibody $(1: 1,000)$ for $1 \mathrm{~h}$ at $25^{\circ} \mathrm{C}$ in the dark. Visualization was performed using a fluorescence microscope and the images were analyzed by Image Pro-Plus 5.1 software (Media Cybernetics, Inc., Rockville, MD, USA). Hoechst 33342 was used as a nuclear counterstain for automated cell identification, and to observe nuclear morphology. This counterstain was also used to determine nuclear size and nuclear staining intensity. Plates were imaged using the Thermo Scientific ArrayScan XTI HCS Reader (Thermo Fisher Scientific, Inc.) and analyzed using the Compartmental Analysis BioApplication (Cellomics, Inc., Thermo Fisher Scientific, Inc.). Immunostaining-based parameters and nuclear staining-based parameters were determined and analyzed in the same image set for each field. For each data replicate, $>3$ fields of view (a total of 500 cells) were analyzed.

ROS measurement. Cells were stained with $5 \mu \mathrm{M}$ cell-permeant 2',7'-dichlorofluorescin diacetate, an oxidative stress indicator (Invitrogen; Thermo Fisher Scientific, Inc.), for $15 \mathrm{~min}$ at $37^{\circ} \mathrm{C}$, washed in PBS, trypsinized and resuspended at $1 \times 10^{6}$ cells $/ \mathrm{ml}$. The dichlorofluorescein signal was observed and analyzed with a FACSCalibur flow cytometer and CELLQuest software version 3.3 (BD Biosciences, Franklin Lakes, NJ, USA). Cells were pre-treated with $10 \mu \mathrm{M}$ CGRP for $24 \mathrm{~h}$, and incubated with air or $60 \%$ oxygen to examine its effects on ROS production. Cells were maintained at $37^{\circ} \mathrm{C}$ for $24 \mathrm{~h}$ and dichlorofluorescein was examined in a $5 \%$ oxygen tissue culture incubator to determine the effect of reduced ambient oxygen on ROS levels.

Apoptosis assay and cell cycle analysis. AEC II were fixed with $70 \%$ ethanol and stored at $4^{\circ} \mathrm{C}$ overnight. Prior to staining, the cell suspension was centrifuged at $500 \times \mathrm{g}$ for $5 \mathrm{~min}$, the pellet was washed with PBS and cells were incubated with propidium iodide for $30 \mathrm{~min}$ at $4^{\circ} \mathrm{C}$ in the dark. Cellular apoptosis and cell death were detected by Annexin V and PI staining with an 
Annexin V-FITC/PI apoptosis detection kit, as described by the manufacturer. Analysis was performed by flow cytometry and Flowjo software 7.6 (FlowJo LLC, Ashland, OR, USA) was used for acquisition and analysis.

Western blotting. AEC II were incubated with RIPA lysis buffer (Beyotime Institute of Biotechnology, Haimen, China) for $15 \mathrm{~min}$ on ice, then centrifuged at $13,000 \times \mathrm{g}$ for $5 \mathrm{~min}$ at $4^{\circ} \mathrm{C}$. A total of $20 \mu \mathrm{g}$ protein from cell lysate was separated by $12 \%$ SDS-PAGE. Wet gel system was used to transfer protein samples to a PVDF membrane. Following 5\% slim milk blocking at room temperature for $1.5 \mathrm{~h}$, the membrane was incubated with a primary anti-caspase 3 antibody (cat. no. sc-7148; 1:500 dilution; Santa Cruz Biotechnology, Inc.,) at $4^{\circ} \mathrm{C}$ overnight and subsequently incubated with a secondary antibody conjugated to horseradish peroxidase (cat. no. sc-2004; 1:2,000 dilution; Santa Cruz Biotechnology, Inc.). $\beta$-actin (cat. no. sc-47778; Santa Cruz Biotechnology, Inc.,) was used as an internal control. Protein images were observed with an electrochemiluminescence solution (Pierce; Thermo Fisher Scientific, Inc.). The experiment was repeated three times.

DNA damage detection by examination of $\gamma \mathrm{H} 2 \mathrm{AX}$ immunofluorescence. ACEII cells were seeded at $2 \times 10^{5}$ cells/well in black 96-well plates with clear, flat bottoms (Costar; Corning Incorporated, Corning, NY, USA). Following treatment, the cells were rinsed with PBS, fixed with $4 \%$ formaldehyde in PBS for $15 \mathrm{~min}$ at room temperature, and permeabilized with $0.1 \%$ Triton X-100 in PBS for 10 min. Nonspecific binding was blocked by incubating the cells with $1 \%$ BSA and $0.02 \%$ Triton $\mathrm{X}-100$ in PBS for $20 \mathrm{~min}$ at room temperature. The cells were sequentially incubated with anti- $\gamma \mathrm{H} 2 \mathrm{AX}$ antibody (dilution, 1:500) for $3 \mathrm{~h}$ at room temperature, Alexa Fluor 488-conjugated anti-rabbit IgG antibody (1:500) at room temperature for $1 \mathrm{~h}$, and Hoechst $33342(10 \mu \mathrm{g} / \mathrm{ml})$ for $10 \mathrm{~min}$. The cells were washed 3 times with $0.02 \%$ Triton X-100 in PBS for $10 \mathrm{~min}$ each time, and were visualized using an ImageXpress Micro Confocal High-Content Imaging System (Molecular Devices, LLC, Sunnyvale, CA, USA). Acquisition and analysis of images, including the number and the total area of $\gamma \mathrm{H} 2 \mathrm{AX}$ foci, were measured using the MetaXpress 4.0.0.24 software (Molecular Devices, LLC). Images of stained cells were acquired from the automated fluorescence microscope platform of the ImageXpress using a 40x objective lens.

Statistical analysis. SPSS 19.0 software (IBM SPSS, Armonk, NY, USA) was used for statistical analyses. All data are expressed as the mean \pm standard deviation. Group means were compared by analysis of variance with Tukey's tests used for post hoc analyses. $\mathrm{P}<0.05$ was considered to indicate a statistically significant difference.

\section{Results}

$C G R P$ reverses the changes in $A E C$ II that are induced by $60 \%$ oxygen. SP-C, secreted only by AEC II, is a biomarker of these cells (19). Therefore, AEC II were first plated on slides and the SP-C expression was detected in situ using immunofluorescence (Fig. 1A). SP-C fluorescence in the cytoplasm was markedly decreased in the hyperoxia groups compared with the air group, and treatment with CGRP partially rescued hyperoxia-treated cells, though treatment with $\mathrm{CGRP}_{8-37}$ (the CGRP receptor antagonist) did not. The fluorescence intensity did not differ among the three groups cultured in air (Fig. 1A). Following each treatment, $\mathrm{SP}-\mathrm{C}$ fluorescence in $\mathrm{O}_{2}$ groups was markedly lower than that in each respective air group.

In order to evaluate the effects of $60 \%$ oxygen to AEC II cells, the levels of ROS in AEC II treated with $60 \%$ oxygen and/or CGRP were assessed using 2',7'-dichlorofluorescein diacetate (Fig. 1B). ROS levels were significantly increased following exposure to $60 \%$ oxygen for $24 \mathrm{~h}$ (Fig. 1B). Administration of $10 \mu \mathrm{M}$ CGRP prior to hyperoxia significantly inhibited the increase in ROS levels observed in the hyperoxia group $(\mathrm{P}<0.05$; Fig. $1 \mathrm{~B})$. To verify these effects, both CGRP and $\mathrm{CGRP}_{8-37}$ were applied to competitively block the binding sites, demonstrating that ROS levels return hyperoxia group levels. These data indicated a protective effect of CGRP against hyperoxia insult (Fig. 1B).

CGRP inhibits apoptosis of AEC II that is induced by hyperoxia. A previous study revealed that $95 \%$ oxygen could induce AEC II apoptosis (20). To investigate the influence of moderate oxygen on AEC II apoptosis, the proportion of apoptotic cells was detected by flow cytometry. The apoptotic cell number increased in the $60 \%$ oxygen groups compared with the air control groups (Fig. 2A and B). The role of CGRP in apoptosis was investigated, revealing that the apoptotic rate significantly decreased in the $\mathrm{CGRP} / \mathrm{O}_{2}$ group compared with the control hyperoxia group $(\mathrm{P}<0.01$; Fig. $2 \mathrm{~B})$. Cells treated with high oxygen expressed active caspase-3, which was inhibited by CGRP treatment (Fig. 2C). These findings indicated that hyperoxia triggered apoptosis, which could be inhibited by CGRP.

Analyses of the relationship between double strand breaks(DSB) and apoptosis. As DSB damage induces apoptosis, cellular senescence and pro-inflammatory cytokine production (21), the presence of $\gamma \mathrm{H} 2 \mathrm{AX}$, a marker of DSB and the effects of CGRP were investigated in AEC II. Analysis of AEC II revealed that the hyperoxia group cells contained higher numbers of $\gamma \mathrm{H} 2 \mathrm{AX}$ foci and CGRP decreased numbers of $\gamma \mathrm{H} 2 \mathrm{AX}$ foci (Fig. 3A). Furthermore, the mean $\gamma \mathrm{H} 2 \mathrm{AX}$ fluorescence measured in these cells demonstrated a dose-dependent trend following treatment with different concentrations of CGRP, indicating that DNA fragmentation was occurring during apoptosis (Fig. 3B). These data suggest that DNA damage is directly linked to the induction of apoptosis in AEC II.

CGRP increases the number of AEC II in S and G2/M phases. Alterations to the cell cycle often involve DNA damage and repair (22). For this reason, the effects of CGRP on the cell cycle of cultured AEC II were determined. AEC II treated with CGRP $(10 \mu \mathrm{M})$, and the proportion of $\mathrm{S}$ and $\mathrm{G} 2 / \mathrm{M}$ phase cells were detected by flow cytometry to judge the effects on proliferation (Fig. 4). CGRP at a concentration of $10 \mu \mathrm{M}$ significantly enhanced the proportion of cells in the S- and G2/M-phases, with a consequent reduction of AEC II in G0/G1 (Fig. 4). No significant differences were observed between the levels of proliferative cells in the air control and the air + CGRP group. 
A

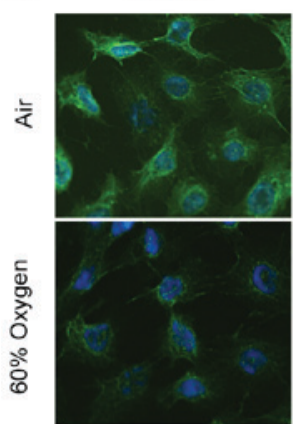

CGRP

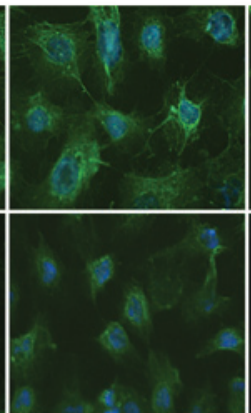

CGRP $_{2,37}$

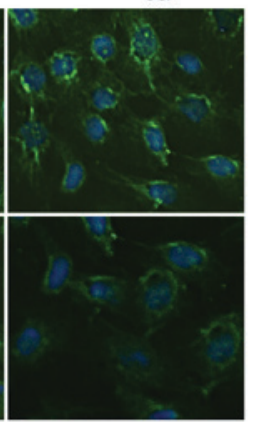

B

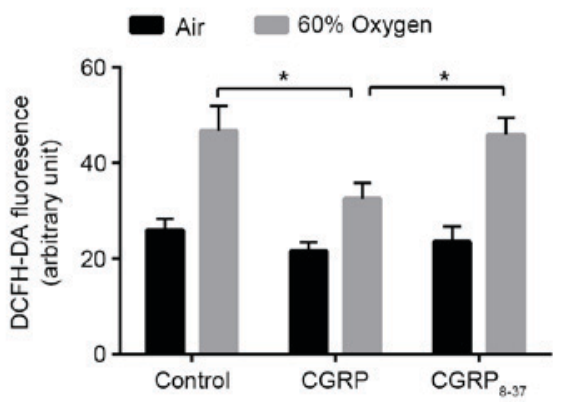

Figure 1. Immunofluorescence of SP-C and ROS levels in AEC II treated with CGRP and/or 60\% oxygen. (A) AEC II double-labeled with anti-SP-C antibodies/Alexa 488 anti-goat immunoglobulin G. Scale bar, $20 \mu \mathrm{m}$. (B) Relative ROS levels in each condition, quantified by dichlorofluorescin fluorescence-activated cell sorting of AEC II. CGRP/CGRP ${ }_{8-37}$ pre-treated cells were incubated with $60 \%$ oxygen for $24 \mathrm{~h}$ before ROS measurement ( $\mathrm{n}=3$ ). Values are reported as mean + standard deviation; P-values were determined by Student's $t$-test. " $\mathrm{P}<0.05$ vs. relevant group. SP-C, surfactant protein-C; ROS, reactive oxygen species; CGRP, calcitonin gene-related peptide; AEC II, alveolar epithelial type II cells.

A
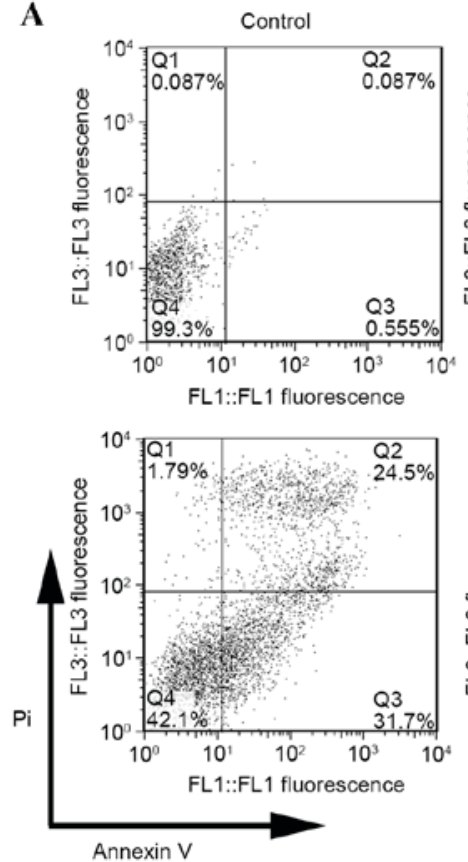
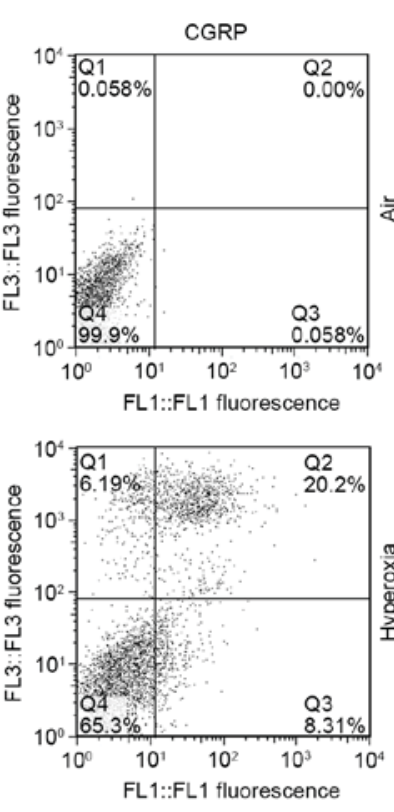

B

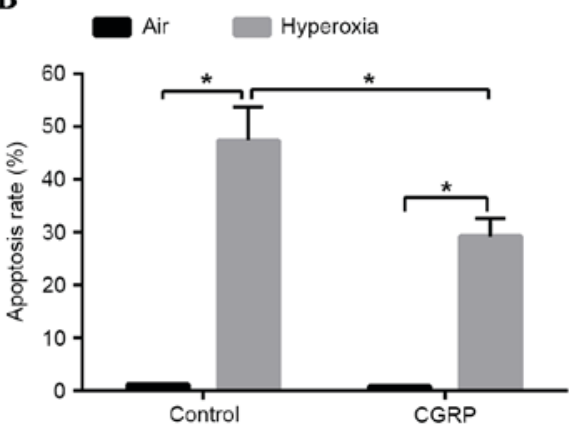

C

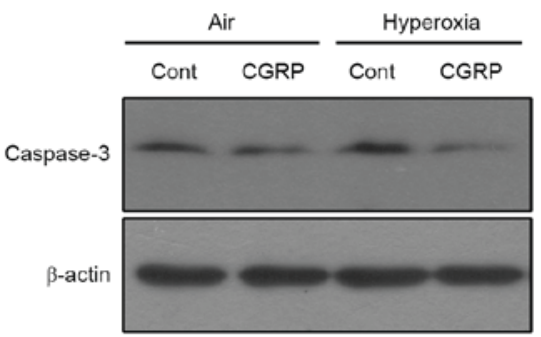

Figure 2. Effects of CGRP on hyperoxia-induced apoptosis in AEC II. (A) Cells were pre-treated with CGRP (10 $\mu \mathrm{M})$ for $4 \mathrm{~h}$ and exposed to $60 \%$ oxygen for $24 \mathrm{~h}$, then apoptotic rate was determined by Annexin V/propidium iodide staining and analysed using flow cytometry. (B) Graphical representation of (A), reported as mean + standard deviation. P-values were determined by Student's $t$-test. "P $<0.01$ vs. relevant group. (C) Cleaved caspase- 3 , examined by western blot analysis. $\beta$-actin was used as a loading control CGRP, calcitonin gene-related peptide; AEC II, alveolar epithelial type II cells.
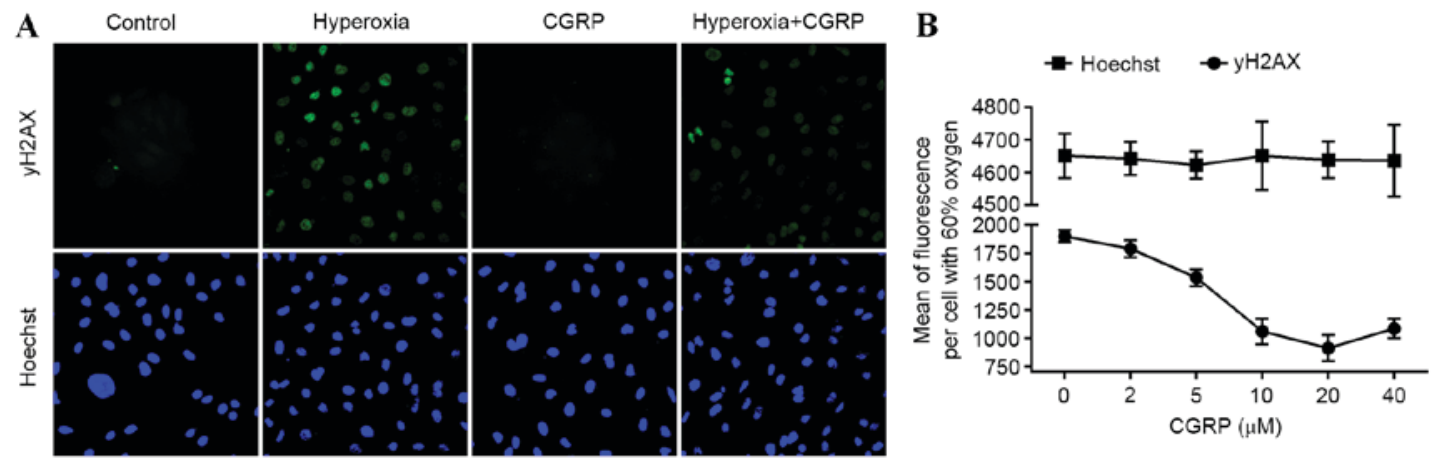

Figure 3. Hyperoxia-induced $\gamma$-H2AX phosphorylation in AEC II in response to CGRP. (A) Visualization of oxidized DNA marker $\gamma \mathrm{H} 2 \mathrm{AX}$ by immunofluorescence in response to CGRP and/or 60\% oxygen conditions. Nuclei are visualized by counterstaining with Hoescht. (B) Relative quantification of mean fluorescence per cell stained by the DNA damage response protein, $\gamma \mathrm{H} 2 \mathrm{AX}$. All cells were incubated for $24 \mathrm{~h}$ in the indicated oxygen conditions before analysis. Values are reported as mean + standard deviation. CGRP, calcitonin gene-related peptide; AEC II, alveolar epithelial type II cells. 

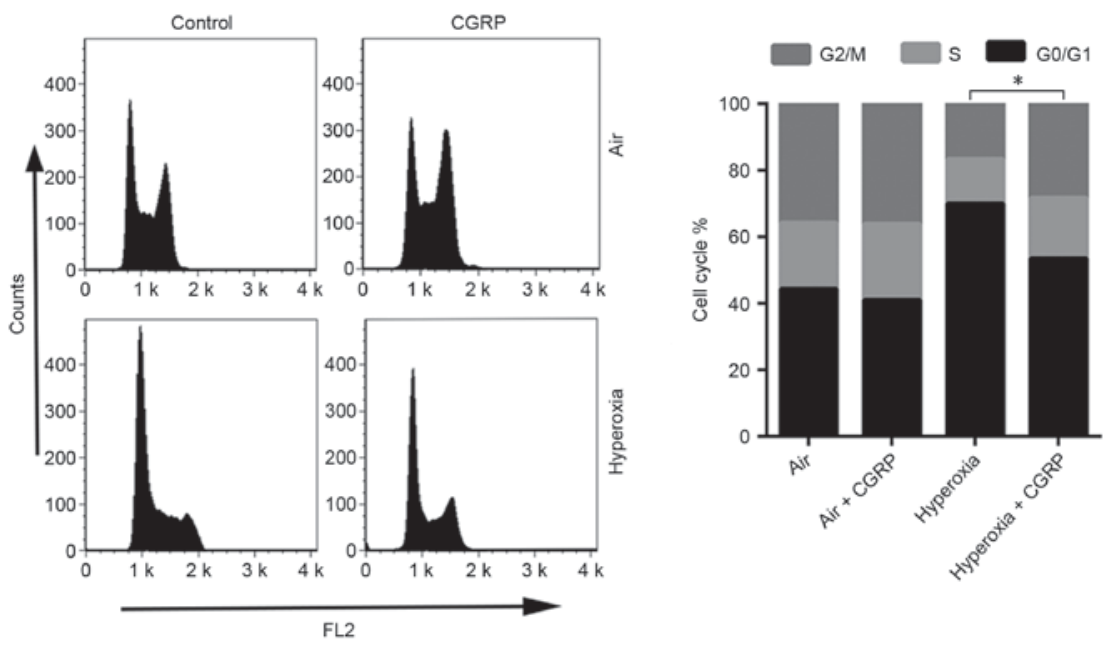

Figure 4. CGRP effects on the cell cycle arrest induced by hyperoxia. The cell cycle distributions of AEC II treated with CGRP and/or $60 \%$ oxygen were determined after $24 \mathrm{~h}$, using flow cytometric analysis. "P<0.05 vs. relevant group. CGRP, calcitonin gene-related peptide; AEC II, alveolar epithelial type II cells.

\section{Discussion}

The present study reported that fetal AEC II exposure to $60 \%$ oxygen for $24 \mathrm{~h}$ causes cellular injury by inducing apoptosis, which may be closely associated with the DNA damage repair mechanism; CGRP may reduce the apoptotic rate induced by high oxygen concentration by blocking DNA damage.

The pattern of lung injury is closely correlated with the oxygen concentration and exposure time (23). The model of hyperoxic lung injury, achieved with an oxygen concentration $>85 \%$, lasted for over 2 days (24). Lee et al (25) isolated AEC II from the lungs of $95 \%$ oxygen-exposed animals and revealed that a sub-lethal exposure time for this cell line was $48 \mathrm{~h}$, whereas $96 \mathrm{~h}$ of exposure was invariably lethal. Similarly, Pace et al (26) demonstrated that $80 \%$ oxygen exposure for $60 \mathrm{~h}$ increased lipid peroxide levels and inflammatory cells in bronchoalveolar lavage. However, most of those studies were conducted on AEC II in vivo or as part of a whole lung homogenate, rather than on cells isolated as a pure population $(5,27,28)$. In the present study, purified AEC II cells were exposed to $60 \%$ oxygen for $24 \mathrm{~h}$, and the detrimental effects of moderate oxygen were investigated. As $60 \%$ oxygen is more frequently used than $90 \%$ in clinical practice, $60 \%$ oxygen was used to attain a valid hyperoxic cell model in the current study.

CGRP, mainly expressed in nerve fibers and in the respiratory system, has multiple effects on cells under physiological and pathological conditions. It can serve as a pro-inflammatory factor by stimulating eosinophil migration, contracting human bronchi and effectively dilating human pulmonary vessels in vitro (29). In contrast, other previous reports demonstrated that CGRP suppresses secretion of inflammatory cytokines, such as IL-6, IL-8 and TNF $\alpha$, from macrophages, suggesting its potential anti-inflammatory properties $(30,31)$. Although CGRP was associated with regulation of inflammatory cytokines, no previous study has related this to DNA damage. The present study indicated that CGRP serves a protective role on hyperoxia-induced AEC II injury by inhibition of oxidative stress and reduction of apoptosis. $\mathrm{H} 2 \mathrm{AX}$ expression was also detected, which is a biomarker of DNA damage, particularly for DSB; this revealed increased expression of $\mathrm{H} 2 \mathrm{AX}$ in AEC II exposed into $60 \%$ oxygen and decreased $\mathrm{H} 2 \mathrm{AX}$ expression in the presence of CGRP, which could be reversed by addition of the CGRP receptor antagonist $\mathrm{CGRP}_{8-37}$.

In addition, to investigate the relationship between CGRP and DNA damage repair, cell cycle changes were examined. It was revealed that $10 \mu \mathrm{M}$ CGRP significantly increased the number of AEC II in S/G2, both in air and hyperoxia conditions, and that its antagonist, $\mathrm{CGRP}_{8-37}$, significantly attenuated the proliferative effect of CGRP. Previous studies documented that hyperoxia exerts inhibition of cell growth $(32,33)$ which is consistent with the current findings that direct exposure of AEC II to $60 \%$ oxygen for $24 \mathrm{~h}$ results in an increase of cells in $\mathrm{G} 0 / \mathrm{G} 1$ and a decrease of cells in S and G2/M phase. It is hypothesized that high oxygen induced DNA damage, leading to AEC II apoptosis, whilst CGRP reduced DNA damage, enhanced the arrest in $\mathrm{S}$ and G2/M phase, promoted cell repair and inhibited apoptosis.

The exact protective mechanisms of CGRP in AEC II under hyperoxia exposure have not been identified in the presently investigated context, and the correlation of CGRP and DNA damage have not been studied. In the present study, CGRP inhibited cell death and DNA damage, which may be indirectly affected by other, associated proteins, rather than direct regulation. A previous study suggested that CGRP binds to receptors expressed on the cell surface of AEC II and activates receptor-coupled $\mathrm{G}$ proteins, leading to an induction of intracellular cyclic AMP (cAMP) generation (34). The accumulated cAMP inhibits the accumulation of $N F-\kappa B$ complexes in the nucleus by preventing phosphorylation and degradation of $\mathrm{I} \kappa \mathrm{B}$, an $\mathrm{NF}-\kappa \mathrm{B}$ inhibitor (35). A previous studies by the current authors has also demonstrated that high oxygen and CGRP affects constitutive membrane transport of protein kinase $\mathrm{C}$ (PKC) $\alpha$, and observed that the activation of $\mathrm{NF}-\kappa \mathrm{B}$ in the nucleus. As PKCa and $\mathrm{NF}-\kappa \mathrm{B}$ appear to serve an important role in apoptosis, it is hypothesized that CGRP inhibits cell damage and apoptosis by activating NF- $\mathrm{NB}$ or PKCa associated pathways (36). However, a previous study confirmed that inhibition of NF- $\kappa \mathrm{B}$ activity would trigger the protective mechanism of CGRP to confine the inflammatory response (37). Therefore, it is difficult to identify whether 
CGRP inhibited DNA damage via NF- $\kappa \mathrm{B}$, and additional studies are required to understand the mechanism behind this.

In conclusion, the present study demonstrated that exposure to $60 \%$ oxygen for $24 \mathrm{~h}$ predisposed AEC II to oxidative injury in vitro, including DNA damage and apoptosis; however, exogenous CGRP markedly attenuated hyperoxic injury and exerted a cytoprotective effect against hyperoxia insult. This suggests that upregulation of CGRP expression may represent an alternative approach for prevention from hyperoxia-induced lung injury.

\section{Acknowledgements}

The present study was supported by the National Natural Science Foundation of China (grant nos. 30470755 and 81260289). Dr Zijie Liu from The First Affiliated Hospital of Kunming Medical University (Kunming, Yunnan, China) is thanked for support in a number of key laboratory techniques.

\section{References}

1. Kallet RH and Matthay MA: Hyperoxic acute lung injury. Respir Care 58: 123-141, 2013.

2. Bellani G, Laffey JG, Pham T, Fan E, Brochard L, Esteban A, Gattinoni L, van Haren F, Larsson A, McAuley DF, et al: Epidemiology, patterns of care, and mortality for patients with acute respiratory distress syndrome in intensive care units in 50 Countries. JAMA 315: 788-800, 2016

3. Singh G, Gladdy G, Chandy TT and Sen N: Incidence and outcome of acute lung injury and acute respiratory distress syndrome in the surgical intensive care unit. Indian J Crit Care Med 18: 659-665, 2014

4. Ward NS, Waxman AB, Homer RJ, Mantell LL, Einarsson O, $\mathrm{Du} \mathrm{Y}$ and Elias JA: Interleukin-6-induced protection in hyperoxic acute lung injury. Am J Respir Cell Mol Biol 22: 535-542, 2000.

5. Fukumoto J, Fukumoto I, Parthasarathy PT, Cox R, Huynh B, Ramanathan GK, Venugopal RB, Allen-Gipson DS, Lockey RF and Kolliputi N: NLRP3 deletion protects from hyperoxia-induced acute lung injury. Am J Physiol Cell Physio 305: C182-C189, 2013.

6. Crapo JD: Morphologic changes in pulmonary oxygen toxicity. Annu Rev Physiol 48: 721-731, 1986.

7. Durr RA, Dubaybo BA and Thet LA: Repair of chronic hyperoxic lung injury: Changes in lung ultrastructure and matrix. Exp Mol Pathol 47: 219-240, 1987.

8. Wang Y, Feinstein SI, Manevich Y, Ho YS and Fisher AB: Lung injury and mortality with hyperoxia are increased in peroxiredoxin 6 gene-targeted mice. Free Radic Biol Med 37: 1736-1743, 2004

9. Warner BB, Stuart LA, Papes RA and Wispe JR: Functional and pathological effects of prolonged hyperoxia in neonatal mice. Am J Physiol 275: L110-L117, 1998.

10. Russo AF: Calcitonin gene-related peptide (CGRP): A new target for migraine. Annu Rev Pharmacol Toxicol 55: 533-552, 2015.

11. Li WJ and Wang TK: Calcitonin gene-related peptide inhibits interleukin-1beta-induced interleukin-8 secretion in human type II alveolar epithelial cells. Acta Pharmacol Sin 27: 1340-1345, 2006.

12. Filomeni G, De Zio D and Cecconi F: Oxidative stress and autophagy: The clash between damage and metabolic needs. Cell Death Differ 22: 377-388, 2015.

13. Bennett MR: Reactive oxygen species and death: Oxidative DNA damage in atherosclerosis. Cir Res 88: 648-650, 2001.

14. Kim SJ, Cheresh P, Williams D, Cheng Y, Ridge K, Schumacker PT, Weitzman S, Bohr VA and Kamp DW: Mitochondria-targeted Ogg1 and aconitase-2 prevent oxidant-induced mitochondrial DNA damage in alveolar epithelia cells. J Biol Chem 289: 6165-6176, 2014.

15. Shao L, Perez RE, Gerthoffer WT, Truog WE and Xu D: Heat shock protein 27 protects lung epithelial cells from hyperoxia-induced apoptotic cell death. Pediatr Res 65: 328-333, 2009.

16. Li Y, Teruya K, Katakura Y, Kabayama S, Otsubo K, Morisawa S, Ishii Y, Gadek Z and Shirahata S: Effect of Reduced Water on the Apoptotic Cell Death Triggered by Oxidative Stress in Pancreatic $\beta$ HIT-T15 Cell. In: Animal cell technology meets Genomics. Springer 2: pp121-124, 2005.
17. Thome UH, Davis IC, Nguyen SV, Shelton BJ and Matalon S: Modulation of sodium transport in fetal alveolar epithelial cells by oxygen and corticosterone. Am J Physiol Lung Cell Mol Physiol 284: L376-L385, 2003.

18. Li Z, Fang F and Xu F: Effects of different states of oxidative stress on fetal rat alveolar type II epithelial cells in vitro and ROSinduced changes in Wnt signaling pathway expression. Mol Med Rep 7: 1528-1532, 2013.

19. Li F, He J, Wei J, Cho WC and Liu X: Diversity of epithelial stem cell types in adult lung. Stem Cells Int 2015: 728307, 2015.

20. De Paepe ME, Mao Q, Chao Y, Powell JL, Rubin LP and Sharma S: Hyperoxia-induced apoptosis and Fas/FasL expression in lung epithelial cells. Am J Physiol Lung Cell Mol Physiol 289: L647-L659, 2005.

21. Kidane D, Chae WJ, Czochor J, Eckert KA, Glazer PM, Bothwell AL and Sweasy JB: Interplay between DNA repair and inflammation and the link to cancer. Crit Rev Biochem Mol Biol 49: 116-139, 2014.

22. Branzei D and Foiani M: Regulation of DNA repair throughout the cell cycle. Nat Rev Mol Cell Biol 9: 297-308, 2008.

23. Jankov RP, Luo X, Campbell A, Belcastro R, Cabacungan J, Johnstone L, Frndova H, Lye SJ and Tanswell AK: Fibroblast growth factor receptor-1 and neonatal compensatory lung growth after exposure to 95\% oxygen. Am J Respir Crit Care Med 167: 1554-1561, 2003.

24. Rogers LK, Tipple TE, Nelin LD and Welty SE: Differential responses in the lungs of newborn mouse pups exposed to $85 \%$ or $>95 \%$ oxygen. Pediatr Res 65: 33-38, 2009.

25. Lee J, Reddy R, Barsky L, Weinberg K and Driscoll B: Contribution of proliferation and DNA damage repair to alveolar epithelial type 2 cell recovery from hyperoxia. Am J Physiol Lung Cell Mol Physiol 290: L685-L694, 2006.

26. Pace PW, Yao LJ, Wilson JX, Possmayer F, Veldhuizen RA and Lewis JF: The effects of hyperoxia exposure on lung function and pulmonary surfactant in a rat model of acute lung injury. Exp Lung Res 35: 380-398, 2009.

27. Michaelis KA, Agboke F, Liu T, Han K, Muthu M, Galambos C, Yang G, Dennery PA and Wright CJ: I $\kappa \beta \beta$-mediated NF- $\kappa$ B activation confers protection against hyperoxic lung injury. Am J Respir Cell Mol Biol 50: 429-438, 2014.

28. Vadivel A, Alphonse RS, Ionescu L, Machado DS, O'Reilly M, Eaton F, Haromy A, Michelakis ED and Thébaud B: Exogenous hydrogen sulfide (H 2 S) protects alveolar growth in experimental O2-induced neonatal lung injury. PLoS One 9: e90965, 2014.

29. Springer J, Geppetti P, Fischer A and Groneberg DA: Calcitonin gene-related peptide as inflammatory mediator. Pulm Pharmacol Ther 16: 121-130, 2003.

30. Nong YH, Titus RG, Ribeiro JM and Remold HG: Peptides encoded by the calcitonin gene inhibit macrophage function. J Immunol 143: 45-49, 1989.

31. Li W, Wang T, Ma C, Xiong T, Zhu Y and Wang X: Calcitonin gene-related peptide inhibits interleukin-1beta-induced endogenous monocyte chemoattractant protein-1 secretion in type II alveolar epithelial cells. Am J Physiol Cell Physiol 291: C456-C465, 2006.

32. Yee M, Vitiello PF, Roper JM, Staversky RJ, Wright TW, McGrath-Morrow SA, Maniscalco WM, Finkelstein JN and O'Reilly MA: Type II epithelial cells are critical target for hyperoxia-mediated impairment of postnatal lung development. Am J Physiol Lung Cell Mol Physiol 291: L1101-L1111, 2006.

33. O'Reilly MA: DNA damage and cell cycle checkpoints in hyperoxic lung injury: Braking to facilitate repair. Am J Physiol Lung Cell Mol Physiol 281: L291-L305, 2001.

34. Drissi H, Lasmoles F, Le Mellay V, Marie PJ and Lieberherr M: Activation of phospholipase C-beta1 via Galphaq/11 during calcium mobilization by calcitonin gene-related peptide. J Biol Chem 273: 20168-20174, 1998.

35. Brigelius-Flohé R, Banning A, Kny M and Böl GF: Redox events in interleukin-1 signaling. Arch Biochem Biophys 423: 66-73, 2004.

36. Fu HM, Li L, Wang YJ, Tang CH, Mi HY, Xu F and Kuang FW: The proliferation-promoting effects of calcitonin gene-related peptide on type II alveolar epithelial cell exposed to hyperoxia mediated by protein kinase $\mathrm{C}$ alpha pathway. Zhongguo Wei Zhong Bing Ji Jiu Yi Xue 22: 263-266, 2010 (In Chinese).

37. Piette J, Piret B, Bonizzi G, Schoonbroodt S, Merville MP, Legrand-Poels $S$ and Bours V: Multiple redox regulation in NF-kappaB transcription factor activation. Biol Chem 378: 1237-1245, 1997. 